(An ISO 3297: 2007 Certified Organization)

Vol. 3, Issue 10, October 2014

\title{
Compact Design of H-Shaped Fractal Microstrip Patch Antenna Using Different DGS for Wireless Applications
}

\author{
Kapil Thakur ${ }^{1}$, Sumit Kaushik ${ }^{2}$ \\ P.G. Student (M.Tech), Dept. of ECE LRIET, SOLAN, Himachal Pradesh, India ${ }^{1}$ \\ Assistant Professor, Dept. of ECE, LRIE T, SOLAN, Himachal Pradesh, India ${ }^{2}$
}

\begin{abstract}
Microstrip antennas find applications in aircraft, satellite and missile applications where important characteristics are size, weight and complexity. Design and simulation has been carried out using IE3D simulation software. Minkowski fractal geometry has been applied on patch of antenna to form self similar H-shaped patch antenna. By applying DGS in horizontal direction and vertical direction, characteristics of antenna are observed. When DGS has been changed in horizontal direction and Fr-4 has been used as substrate then antenna resonated at $2.7 \mathrm{GHz}$, $4.8 \mathrm{GHz}$ and $6.2 \mathrm{GHz}$ with return loss of $-17.66 \mathrm{~dB},-13.6 \mathrm{~dB}$ and $-23.66 \mathrm{~dB}$. This antenna has gain of $6.05 \mathrm{dBi}, 5.6$ $\mathrm{dBi}$ and $3.66 \mathrm{dBi}$. Results are also obtained for $\mathrm{H}$-shaped fractal patch antenna by applying plus shaped DGS and slot shaped DGS, hence antenna can be used for WLAN applications. When microstrip feed line has been used, proposed antenna can be useful for GPS application.
\end{abstract}

KEYWORDS: Fractal, H shape, Patch, Patch antenna, IE3D

\section{INTRODUCTION}

Today's in antenna field the scenario is such as the low profile, the ease of fabrication and the low cost can made this element very popular and attracted and this is the main advantage of microstrip patch antenna and also implemented in our work. The above-mentioned merits would be expected to project the patch is better for many applications, its large physical size renders it improper where the antenna space availability is a limitation. It has been considered several methods to reduce the antenna size such as the use of shorting pins [3], material loading and geometry optimization [4]. Although it is interesting to conclude that attempts to increase the conductive patch of the antenna have been endeavored by introducing slots, defected ground structures [12] and notches [4,5]. There are number of techniques for improving characteristics of microstrip patch antenna which include making use of fractal geometry, defected ground structure and cutting slots on patch. Fractal means broken or irregular fragments. There are number of fractal shapes like Minkowski, Hilbert curve, Koch curve, Sierpinski and fractal arrays.[13] By applying fractal geometry on patch, area of patch decreases, resonant length increases and number of frequency bands of antenna increases. Since it is also important to have wideband characteristics, hence defected ground structure plays an important role in improving bandwidth of antenna. If one applies both fractal geometry as well as DGS characteristics of antenna gets improved.

\section{RELATED WORK}

H-shaped fractal microstrip patch antenna with DGS has been designed for wireless applications. Microstrip antennas [4] are useful because of their advantages like low cost, small size and they are easy to fabricate. But they are having some of disadvantages like small bandwidth, less gain and lack of multiband characteristics. Hence literature survey had been carried out so as to know about techniques used in improving characteristics. Different types of slots can be made on the patch of antenna. Rectangular microstrip slot monopole antenna with hook shaped arm was made on a thin substrate [7] to achieve large bandwidth. Proposed antenna covered WLAN and Wi-MAX frequency band applications. Miniaturized inverted $\mathrm{F}$ antenna had been used for wireless sensor network applications [12]. . Tree shape fractal geometry [1] had been used for RFID readers and tag. The reader antenna had a $-10 \mathrm{~dB}$ bandwidth of $248 \mathrm{MHz}, 398$ $\mathrm{MHz}$ and $405 \mathrm{MHz}$ at $3.6 \mathrm{GHz}, 5.8 \mathrm{GHz}$ and $8.2 \mathrm{GHz}$ respectively. Minkowski fractal geometry [6] had been used to 


\title{
International Journal of Innovative Research in Science, Engineering and Technology
}

\author{
(An ISO 3297: 2007 Certified Organization)
}

\section{Vol. 3, Issue 10, October 2014}

design fractal antenna up to third iteration. This antenna was having different frequency bands with less return loss, high efficiency and broad bandwidth at final iteration with a gain of $5.4 \mathrm{dBi}$. Fractal monopole antenna was obtained with Giuseppe and Peano fractal geometries [8]. This antenna design was combination of two fractal geometries. Two iterations of fractal geometry were applied to obtain good characteristics but this shape was complex from fabrication point of view. Stacked fractal patch antenna had been used to reduce radio interference for GPS application. This configuration suffer from disadvantage that it had large size and also used two patch elements. Microstrip patch antenna was designed in stacked configuration. Fractal shaped defects in form of Koch curves had been removed from patch surfaces [2]. This antenna was having impedance bandwidth of $120 \mathrm{MHz}$ and $160 \mathrm{MHz}$ at two frequency bands 2.4 GHz and 5.8 GHz. Sierpinski fractal antennas [9] had been designed. Proposed antenna had a bandwidth of 868 $\mathrm{MHz}$ and return loss of $-16 \mathrm{~dB}$. Antenna was designed using cantor shape fractal antenna [11] for different wireless applications. Although this antenna had good bandwidth and gain but size of this antenna is $28 \mathrm{X} 38 \mathrm{~mm}^{2}$. Dual frequency antenna [5] was obtained by replacing a segment of square ring antenna by fractal Minkowski curve. This antenna had compact size but had one drawback. This antenna was having very small bandwidth. From above discussion, it is found that factors which are necessary for optimized antenna design are good bandwidth, small size, simple design, good gain and less return loss.

There are different steps that have been followed in order to achieve the objective of dissertation:

- $\quad$ Fractal antenna dimensions calculated before design using IE3D software.

- Design, simulation and analysis are carried out using IE3D software.

Finally simulation and testing results are compared. Earlier work done on microstrip antenna has been discussed. There are different aspects of microstrip antenna like fractal geometry and DGS are discussed. Different challenges were analyzed on the basis of shortcomings of these aspects. Problem had been formulated on the basis of different challenges analyzed from challenges. Depending on problem formulation, objectives and methodology for problem are decided.

\section{Objectives}

- $\quad$ To find the gaps of literature survey.

- $\quad$ Design and simulation of H-shaped fractal microstrip patch antenna with coaxial feeding technique using IE3D.

- Optimization of antenna parameters for bandwidth, gain and return loss by the use of fractal configurations and its testing through IE3D.

\section{DESIGN AND IMPLEMENTATION}

Multiband fractal patch antenna has been designed using Minkowski fractal geometry. Minkowski fractal antenna has been designed by applying three iterations of fractal geometry to form self-similar structures. $\mathrm{H}$ shaped fractal patch antenna is obtained by three iterations of fractal geometry to form self-similar geometry. Further it is found that by changing substrate, good bandwidth of $1.1 \mathrm{GHz}$ in $\mathrm{C}$ band is obtained. Parametric analysis can be obtained by varying substrate thickness, feed point and other parameters. Design and simulation has been carried out using IE3D.Antenna shown in figure 1 is modified by applying Minkowski fractal geometry on both parallel sides of square patch to form $\mathrm{H}$ shaped antenna. This antenna is obtained by making slots to form $\mathrm{h}$ shaped antenna. This $\mathrm{h}$ shaped antenna is further made by applying two iterations of fractal geometries. Minkowski algorithm as shown in figure 1is shown. Here entire length is divided into three equal parts. Minkowski algorithm is applied to length of L mm.

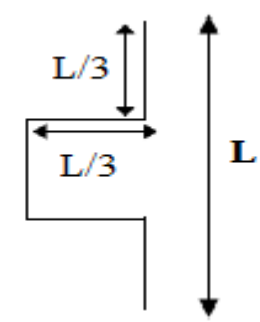

Figure 1: Fractal Geometry Algorithm used [5] 


\section{International Journal of Innovative Research in Science, Engineering and Technology}

\section{(An ISO 3297: 2007 Certified Organization)}

\section{Vol. 3, Issue 10, October 2014}

In this design square patch is having a length of $27 \mathrm{~mm}$. FR-4 has been used as substrate and coaxial feed is used and feed point selected in such a way that impedance matching takes place. This fractal antenna is obtained by applying two iterations of fractal geometry. Table 1 shows dimensions of antenna. Minkowski fractal geometry algorithm has been applied to square patch and different fractal geometry iterations are shown by figure 2(a), (b), 2(c) and 2(d). In these geometries base shape repeats itself. Here square patch having a length of $27 \mathrm{~mm}$ is taken as shown in figure 2(a) and coaxial feed has been given at $(10,9,0)$.

Table 1: Dimensions of H-Shaped FMPA

\begin{tabular}{|l|l|}
\hline Variable & Value \\
\hline Length of patch & $27 \mathrm{~mm}$ \\
\hline Width of patch & $27 \mathrm{~mm}$ \\
\hline Length of ground & $41 \mathrm{~mm}$ \\
\hline Width of ground & $41 \mathrm{~mm}$ \\
\hline Thickness of substrate & $2.4 \mathrm{~mm}$ \\
\hline Feeding technique used & $\begin{array}{l}\text { Coaxial } \\
\text { technique }\end{array}$ \\
\hline Substrate used & FR4 epoxy \\
\hline Feed Point & $(11,9,0)$ \\
\hline $\begin{array}{l}\text { Length of } 1^{\text {st }} \\
\text { fractal cut }\end{array}$ & $9 \mathrm{~mm}$ \\
\hline
\end{tabular}

Feed point has been chosen in such a way that impedance matching take place. I-shaped patch as shown in figure 2(b) is made by using concept of fractal geometry. Vertical length of $27 \mathrm{~mm}$ is divided into 3 parts, each of length 9 mm. these two cuts are made in vertical direction to form $h$ shape patch. $H$ shaped patch Vs having five squares. This $h$ shaped patch is example of microstrip patch antenna with slot cut inside it.

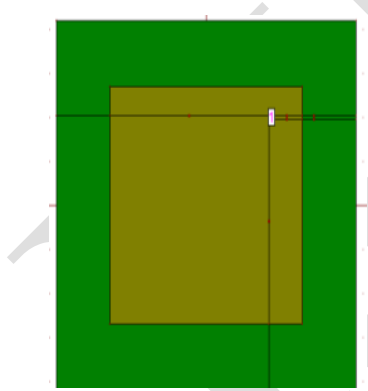

(a)

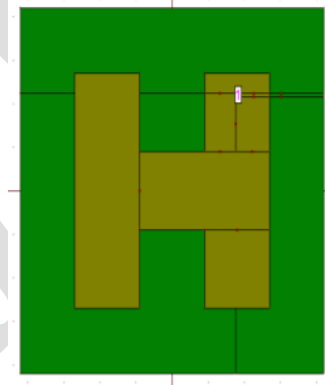

(b)

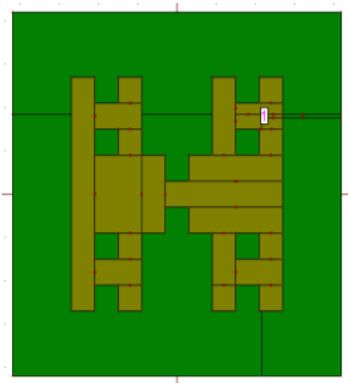

(c)

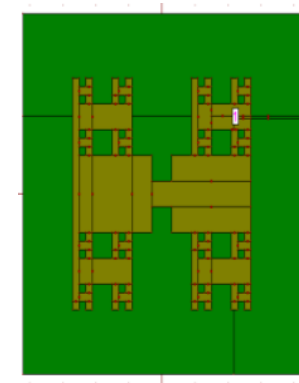

(d)

Figure 2: H-Shaped FMPA (a) $0^{\text {th }}$ Iteration, (b) $1^{\text {st }}$ Iteration , (c) $2^{\text {nd }}$ Iteration and (d) $3^{\text {rd }}$ Iteration

Now to make h shaped fractal square cuts of length $3 \mathrm{~mm}$ are made in each square if dimension $9 \mathrm{~mm}$. As design is made using IE3d simulation software, hence for making cuts, one has to consider center of square. Hence squares of dimension $3 \mathrm{~mm}$ are made to cut from that of $9 \mathrm{~mm}$. Now figure is obtained as shown in figure 2(c). Further to make antenna third iteration of fractal geometry is applied in which squares of dimension $1 \mathrm{~mm}$ are made to cut from $3 \mathrm{~mm}$ length square. Hence $\mathrm{h}$ shaped fractal patch antenna is obtained in which small $\mathrm{h}$ Shaped antenna are repeated with dimension $1 \mathrm{~mm}$ as shown in figure 2(d). Feed to antenna is given coaxial feed at feed point $(11,9$, 0). From these geometries, it is found that self-similar characteristics are obtained. These geometries show self-repeating structures. 


\title{
IIIRSET \\ International Journal of Innovative Research in Science, Engineering and Technology
}

ISSN: 2319-8753

\author{
(An ISO 3297: 2007 Certified Organization)
}

Vol. 3, Issue 10, October 2014

From figure 2, it is clear that size of $\mathrm{h}$ shape is goes on decreasing but resonant length goes on increasing and area goes on decreasing.

\section{RESULTS AND DISCUSSIONS}

In this section result of different iterations of cantor fractal geometry applied on square patch antennas are discussed. Figure 3 represents different fractal geometry iterations of reference antenna. Return loss vs. frequency curve for different fractal geometry iterations are shown in figure 3. From figure 3 it is found that fractal geometry helps in improving antenna characteristics. Antenna at zeroth iteration resonates at $2.8 \mathrm{GHz}$ with return loss of $-12.55 \mathrm{~dB}$, gain of $2.15 \mathrm{dBi}$, directivity of $9.09 \mathrm{dBi}$ and bandwidth of $240 \mathrm{MHz}$ By applying first iteration of fractal geometry, antenna resonates at $6 \mathrm{GHz}$ with return loss of $-13.59 \mathrm{~dB}$, gain of $2.38 \mathrm{dBi}$, directivity of $6.55 \mathrm{dBi}$ and bandwidth of $410 \mathrm{MHz}$ By applying second iteration of fractal geometry, antenna resonates at $4.65 \mathrm{GHz}$ and $6.17 \mathrm{GHz}$ with return loss of $18.76 \mathrm{~dB},-12.04 \mathrm{~dB}$, gain of $1.71 \mathrm{dBi}$ and $3.11 \mathrm{dBi}$, bandwidth of $150 \mathrm{MHz}$ and $320 \mathrm{MHz}$ at corresponding frequencies. When next iteration of fractal geometry is applied, characteristics slightly improves as antenna resonated at two bands namely $4.63 \mathrm{GHz}$ and $6.2 \mathrm{GHz}$ with return loss of $-18.76 \mathrm{~dB},-12.04 \mathrm{~dB}$ and $-18.76 \mathrm{~dB}$, gain of $1.52 \mathrm{dBi}$ and $2.78 \mathrm{dBi}$ and directivity of $2.44 \mathrm{dBi}$ and $8.25 \mathrm{dBi}$ Table 2 shows comparison of results of different iterations of cantor fractal geometry applied on square patch as shown in figure 3. These results shows as number of iterations show as number of iterations increased, a characteristic of antenna begins to improve. Results of return loss versus bandwidth showed that antenna characteristics will be good as number of iterations increases in terms of return loss, bandwidth and frequency.

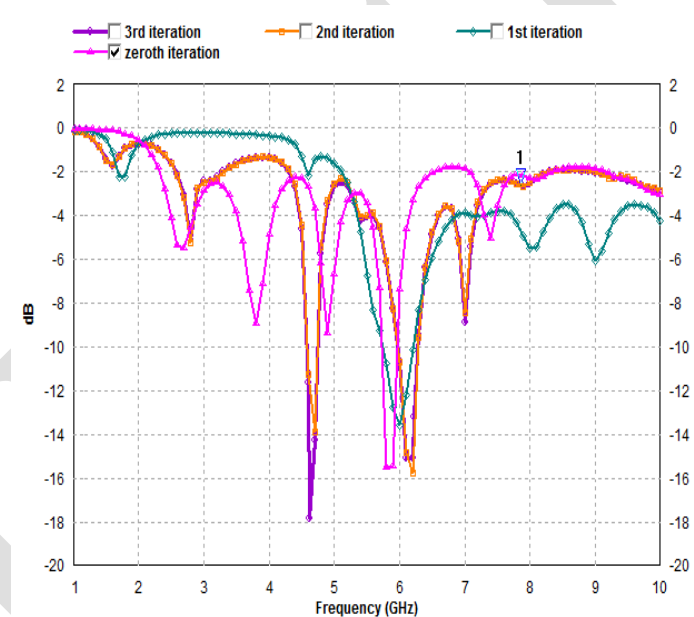

Figure 3: Return Loss vs. Frequency for Different Fractal Iterations of H-Shaped FMPA

Results are analyzed in terms of return loss, gain, directivity and bandwidth. From this table it is found that as number of iterations increases, resonant length increase, area decreases but number of bands increases. Here antenna is having bandwidth of $300 \mathrm{MHz}$ in $\mathrm{C}$ band which could be improved.

Table 2: Comparison Results of Different Iterations of H-shaped FMPA

\begin{tabular}{|l|l|l|l|l|l|}
\hline $\begin{array}{l}\text { Iteratio } \\
\text { n } \\
\text { Number }\end{array}$ & $\begin{array}{l}\text { Resonan } \\
\text { ce } \\
(\mathbf{G H z})\end{array}$ & $\begin{array}{l}\text { Retur } \\
\text { n Loss } \\
(\mathbf{d B})\end{array}$ & $\begin{array}{l}\text { Gain } \\
(\mathbf{d B i})\end{array}$ & $\begin{array}{l}\text { Direc } \\
\text { tivity } \\
(\mathbf{d B i})\end{array}$ & $\begin{array}{l}\text { Band } \\
\text { width } \\
(\mathbf{M H z})\end{array}$ \\
\hline $0^{\text {th }}$ & $5.8 \mathrm{GHz}$ & -15.55 & 2.15 & 9.09 & 240 \\
\hline $1^{\text {st }}$ & $6 \mathrm{GHz}$ & -13.59 & 2.38 & 6.55 & 410 \\
\hline $2^{\text {nd }}$ & 4.65 & -17.76 & 1.71 & 5.48 & 150 \\
& $\mathrm{GHz}$ & & & & \\
\cline { 2 - 6 } & 6.17 & -14.04 & 3.11 & 8.60 & 300 \\
& $\mathrm{GHz}$ & & & & \\
\hline
\end{tabular}




\section{International Journal of Innovative Research in Science, Engineering and Technology}

(An ISO 3297: 2007 Certified Organization)

Vol. 3, Issue 10, October 2014

\begin{tabular}{|l|l|l|l|l|l|}
\hline $3^{\text {rd }}$ & $\begin{array}{l}4.65 \\
\mathrm{GHz}\end{array}$ & -18.76 & 1.52 & 5.44 & 150 \\
\cline { 2 - 6 } & 6.17 & -15.04 & 2.78 & 8.25 & 320 \\
& $\mathrm{GHz}$ & & & & \\
\hline
\end{tabular}

From these, it is found that, as number of iterations, An increase, results improves but complexity increases. Radiation pattern corresponding to that of antenna shown in figure 2(d) is shown in figure 4. These radiation patterns correspond to that of frequency 4.63 and $6.2 \mathrm{~dB}$ as shown in figure $3(\mathrm{a})$ and $3(\mathrm{~b})$.

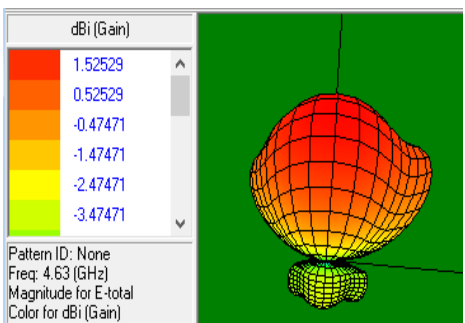

(a)

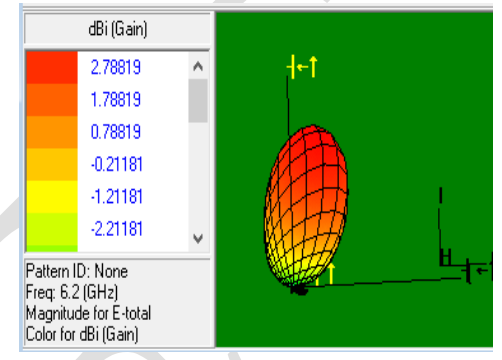

(b)

Figure 4: Radiation Pattern of Reference Antenna at (a) $4.63 \mathrm{GHz}$ and (b) $6.2 \mathrm{GHz}$

\section{EFFECT OF APPLYING DGS}

By applying dumbbell shape DGS in vertical direction to ground plane of fractal antenna as shown in figure 6 is obtained. Further results are analyzed. This dumbbell cut on ground consists of two square heads which are joined by a rectangle of particular slot length and slot width. The geometry of horizontal dumbbell shape DGS has been shown in figure 5. This dumbbell cut on ground helps in reducing area of ground plane and improving bandwidth at different frequencies. Dumbbell made on ground depends on size of square heads joined by rectangular slit.

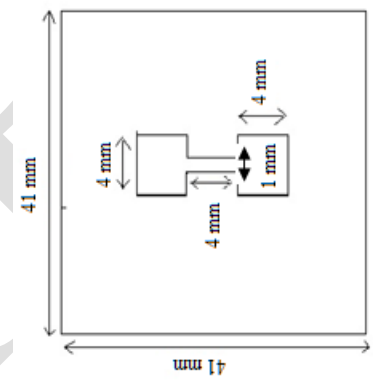

Figure 5: Dumbbell Shape DGS in Horizontal Direction

This DGS is made on ground plane of antenna. It consist of two square heads of $4 \mathrm{~mm}$ length joined by rectangle with slot length of $4 \mathrm{~mm}$, slot width of $1 \mathrm{~mm}$ and is made in vertical direction. Top and bottom view of proposed antenna with DGS are shown in figure 6 (a) and 6 (b).
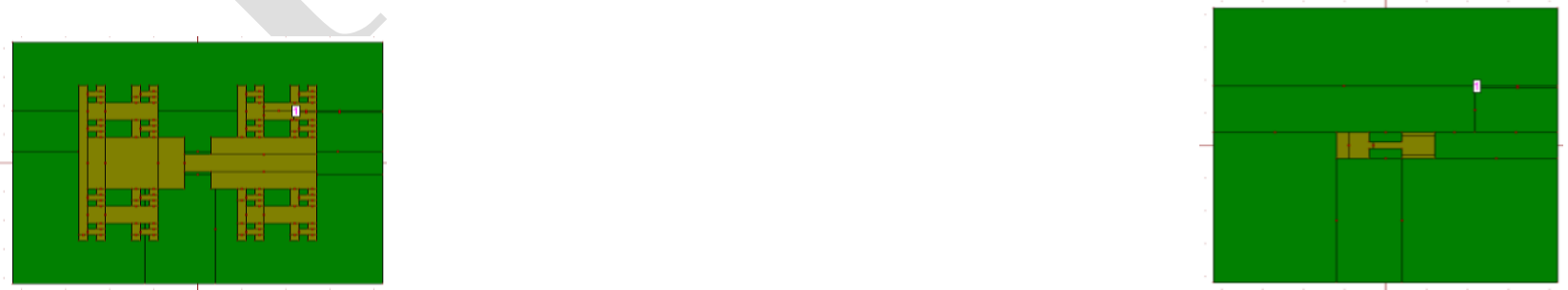

(a)

(b)

Figure 6: Antenna with Horizontal Dumbbell DGS (a) Top View and (b) Bottom View 


\title{
International Journal of Innovative Research in Science, Engineering and Technology
}

\author{
(An ISO 3297: 2007 Certified Organization)
}

\section{Vol. 3, Issue 10, October 2014}

There are many techniques for improving bandwidth of antenna. In this dissertation dumbbell shape DGS has been used. Initially square patch with a length of $27 \mathrm{~mm}$ is taken and two different iterations of fractal geometry are applied one by one to it. Feed to antenna is given at $(11,9$, and 0$)$ and FR-4 has been used as substrate. Dumbbell shape DGS as shown in figure 7 has been applied to ground plane but in a horizontal direction.

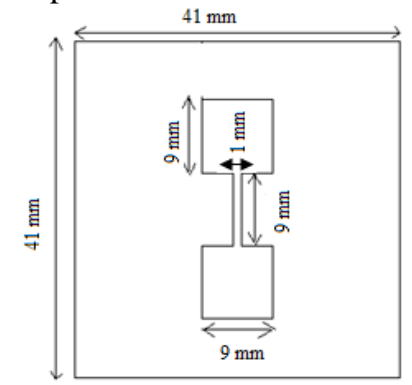

Figure 7: Vertical Dumbbell Shaped DGS

This DGS consists of two square dumbbell heads joined by rectangle having particular slot length and width. When DGS is applied to ground plane, area of ground plane decreases which causes bandwidth of antenna to improve. Top and bottom view of proposed antenna with DGS are shown in figure 8(a) and 8(b).

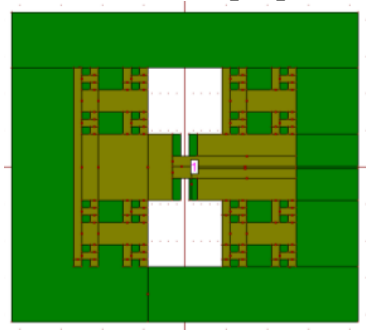

(a)

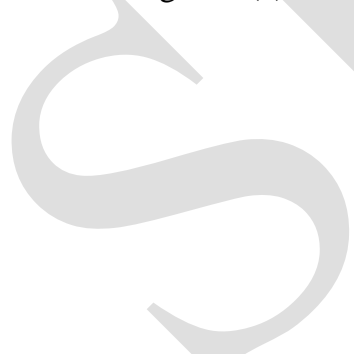

Figure 8: Antenna with Vertical DGS (a) Top View and (b) Bottom View

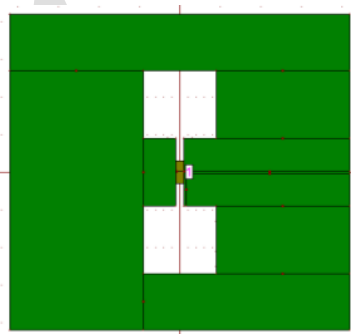

(b)

By applying this DGS to ground plane of antenna, characteristics of antenna are analyzed. Each dumbbell head of dumbbell head is a square having a length of $9 \mathrm{~mm}$. Two square dumbbell heads are joined by a rectangle having a slot length of $9 \mathrm{~mm}$ and slot width of $1 \mathrm{~mm}$. Here DGS has been cut in horizontal direction. By applying DGS along horizontal direction, antenna characteristics improved in terms of return loss, bandwidth and gain. Earlier antenna geometry was modified by changing DGS and analyzing its results. In By using Rogers RT-Duroid/5880 as substrate, bandwidth of $1.1 \mathrm{GHz}$ in $\mathrm{C}$ band is obtained. Rogers RT-Duroid/5880 is having dielectric constant of 2.2 which is half to that of FR4 and it has also loss tangent of 0.0009 . Here ground plane is square with a length of $41 \mathrm{~mm}$. Coaxial feed is used at feed point of $(1,0,0)$. All specifications of antenna are same as in table 2 but substrate has been changed. Further dumbbell shape DGS as shown in figure 9 has been applied to ground plane. Each dumbbell head is a square having a length of $9 \mathrm{~mm}$. Two square dumbbell heads are joined by a rectangle having a slot length of $9 \mathrm{~mm}$ and slot width of $1 \mathrm{~mm}$. above fractal antenna using Rogers RT-Duroid/5880 as substrate. By using this substrate, antenna resonates at three bands with good gain and bandwidth.

\subsection{Antenna with slot cut DGS}

There are different DGS configurations. One of important configurations is obtained by cutting seven slots of dimension $10 \times 2 \mathrm{~mm}^{2}$. These types of DGS decreases ground area and changes inductance and capacitance which changes resonant frequency. This antenna had resonant band but DGS is obtained such that seven continuous slots are made at regular distances. Feed to antenna is coaxial feed with fed point at $(11,9$, and 0$)$. This antenna had geometry top and bottom view of it has been shown in figure 9 (a) and 9 (b). 
ISSN: 2319-8753

\title{
International Journal of Innovative Research in Science, Engineering and Technology
}

\author{
(An ISO 3297: 2007 Certified Organization)
}

Vol. 3, Issue 10, October 2014

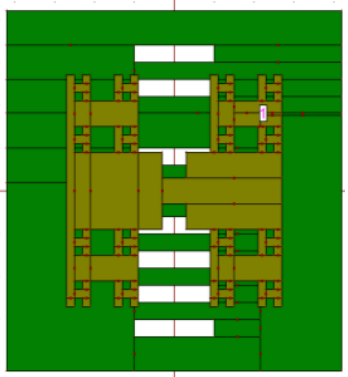

(a)

Figure 9: Antenna with slot DGS (a) Top View and (b) Bottom View

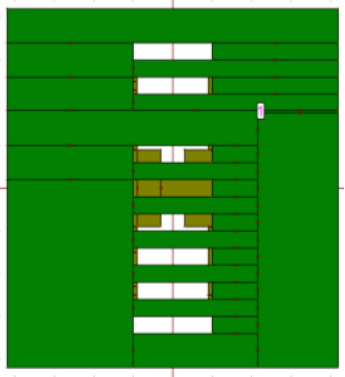

(b)

\subsection{Antenna with plus shaped DGS}

Plus shaped DGS is obtained by cutting plus shaped DGS. This type of DGS is made by cutting two strips one in horizontal and second in vertical direction. These two strips are made in two directions $20 \times 2 \mathrm{~mm}^{2}$. By joining these strips plus shape is obtained. Geometry corresponding to it is shown in figure 10(a) and 10(b). These DGS shows effect of DGS on antenna performance.

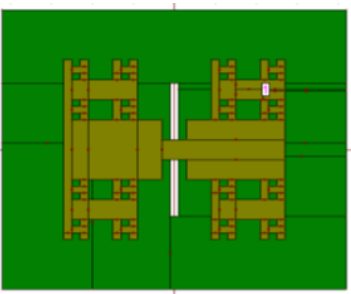

(a)

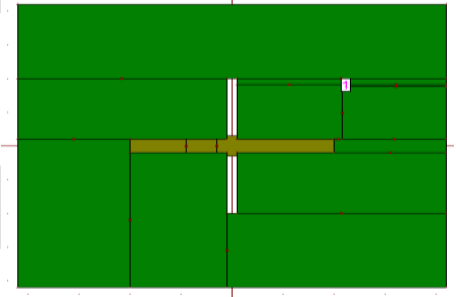

(b)

Figure10: Antenna with DGS using Different Substrate (a) Top View and (b) Bottom View

\section{SIMULATION RESULTS OF H-SHAPED FRACTAL PATCH ANTENNA USING DGS}

Since by applying fractal geometry, characteristics of antenna improved but bandwidth needs to be improved. In this sect ion effects of applying different DGS on ground plane of fractal antenna are analyzed in terms of antenna characteristics.

\subsection{Fractal Antenna with Dumbbell shaped DGS}

Simulated results of applying fractal geometry on patch have been shown in figure 9 in which fractal antenna resonates at two frequencies. There are different DGS configurations namely vertical and horizontal dumbbell DGS. Return loss versus frequency curve is shown in figure 11.

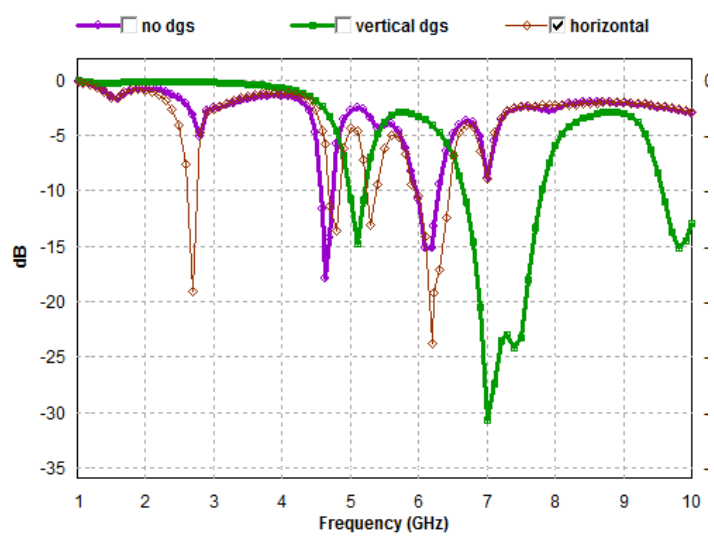

Figure 11: Return Loss Vs Frequency for Antenna with different DGS 


\section{IIIRSET \\ International Journal of Innovative Research in Science, Engineering and Technology}

ISSN: 2319-8753

\section{(An ISO 3297: 2007 Certified Organization)}

\section{Vol. 3, Issue 10, October 2014}

By applying second iteration of fractal geometry, antenna resonates at $4.65 \mathrm{GHz}$ and $6.17 \mathrm{GHz}$ with return loss of $18.76 \mathrm{~dB},-15.04 \mathrm{~dB}$, gain of $1.71 \mathrm{dBi}$ and $3.11 \mathrm{dBi}$, bandwidth of $150 \mathrm{MHz}$ and $320 \mathrm{MHz}$ at corresponding frequencies. By applying DGS in horizontal direction, a characteristic of antenna improves. This antenna is made by changing substrate. This antenna resonates at $5.1 \mathrm{GHz}, 7 \mathrm{GHz}$ and $9.8 \mathrm{GHz}$ with resonant frequency of $-15 \mathrm{~dB},-31.1$ $\mathrm{dB}$ and $-15.3 \mathrm{~dB}$, with bandwidth of $200 \mathrm{MHz}, 1100 \mathrm{MHz}$ and $550 \mathrm{MHz}$ When DGS has been changed in horizontal directional and Fr-4 has been used as substrate then antenna resonated at $2.7 \mathrm{GHz}, 4.8 \mathrm{GHz}$ and $6.2 \mathrm{GHz}$ with return loss of $-17.66 \mathrm{~dB},-13.6 \mathrm{~dB}$ and $-23.66 \mathrm{~dB}$. This antenna has gain of $6.05 \mathrm{dBi}, 5.6 \mathrm{dBi}$ and $3.66 \mathrm{dBi}$. Radiation Pattern of antenna at different frequencies has been shown in figure 12 (a), 12 (b) and 12 (c) corresponding to $2.7 \mathrm{GHz}, 4.8$ $\mathrm{GHz}$ and $6.2 \mathrm{GHz}$.

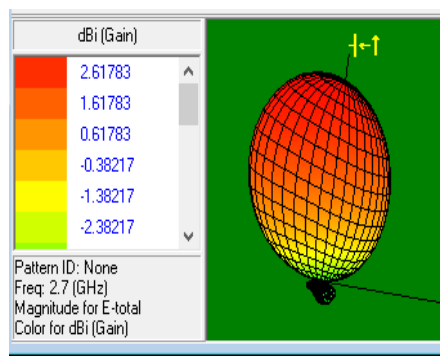

(a)

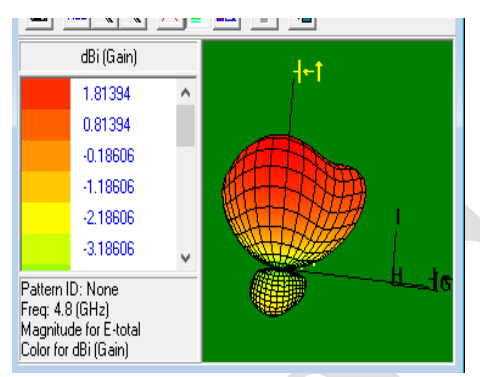

(b)

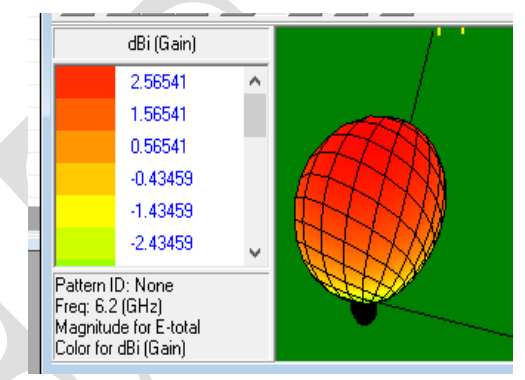

(c)

Figure 12: Radiation Pattern of antenna with Vertical Dumbbell DGS at (a) $2.7 \mathrm{GHz}$, (b) $4.8 \mathrm{GHz}$ and (c) $6.2 \mathrm{GHz}$

By applying vertical dumbbell DGS, results in terms of return loss, bandwidth, gain and directivity are analyzed in table 3.

Table 3: Antenna Characteristics by Dumbbell DGS

\begin{tabular}{|l|l|l|l|l|l|}
\hline $\begin{array}{l}\text { DGS } \\
\text { type }\end{array}$ & $\begin{array}{l}\text { Resonance } \\
\text { Frequency } \\
(\mathbf{G H z})\end{array}$ & $\begin{array}{l}\text { Return } \\
\text { Loss } \\
(\mathbf{d B})\end{array}$ & $\begin{array}{l}\text { Gain } \\
(\mathbf{d B i})\end{array}$ & $\begin{array}{l}\text { Directivity } \\
(\mathbf{d B i})\end{array}$ & $\begin{array}{l}\text { Bandwidth } \\
(\mathbf{M H z})\end{array}$ \\
\hline \multirow{2}{*}{ No } & $4.65 \mathrm{GHz}$ & -17.76 & 1.71 & 5.48 & $\mathbf{1 5 0}$ \\
\cline { 2 - 6 } & $6.17 \mathrm{GHz}$ & -14.04 & 3.11 & 8.60 & $\mathbf{3 0 0}$ \\
\hline $\begin{array}{l}\text { Vertical } \\
\text { dgs }\end{array}$ & 2.7 & -17.66 & 2.61 & 6.42 & $\mathbf{1 0 0}$ \\
\cline { 2 - 6 } & 4.8 & -13.6 & 1.81 & 5.29 & $\mathbf{1 5 0}$ \\
\cline { 2 - 6 } & 6.2 & -23.4 & 2.56 & 7.64 & $\mathbf{4 5 0}$ \\
\hline \multirow{2}{*}{$\begin{array}{l}\text { substrate } \\
\text { dgs }\end{array}$} & 5.1 & -15 & 6.05 & 6.77 & $\mathbf{2 0 0}$ \\
\cline { 2 - 6 } & 7 & -31.1 & 5.6 & 7.1 & $\mathbf{1 1 0 0}$ \\
\cline { 2 - 6 } & 9.8 & -15.3 & 3.66 & 6 & $\mathbf{5 5 0}$ \\
\hline
\end{tabular}

Further from analysis shown in table 3 it is found that by applying vertical dumbbell DGS, antenna resonates at three bands with good bandwidth. Hence this configuration of antenna can be used for different wireless applications.

\subsection{Plus and Slot DGS}

Results were analyzed by applying vertical and horizontal dumbbell DGS. Return loss versus frequency characteristics were obtained by using cross shaped DGS and slot cut DGS as shown in figure 13. By applying slot shaped DGS, antenna shows improvement in characteristics. The antenna with such confuigration can have application for different purposes. By applying plus shaped DGS, antenna resonated at $2.4 \mathrm{GHx}, 5.1 \mathrm{GHz}$ and $6.4 \mathrm{GHz}$ with return loss of - 


\section{IIIRSET \\ International Journal of Innovative Research in Science, Engineering and Technology}

ISSN: 2319-8753

(An ISO 3297: 2007 Certified Organization)

Vol. 3, Issue 10, October 2014

$24.75 \mathrm{~dB},-22.5 \mathrm{~dB}$ and $-21.5 \mathrm{~dB}$, gain of $2.48 \mathrm{dBi}, 1.95 \mathrm{dBi}$ and $2.90 \mathrm{dBi}$. By applying slot cut DGS, antenna resonated at $2.7 \mathrm{Ghz}, 4.5 \mathrm{GHz}$ and $6 \mathrm{GHz}$. This antenna had return loss of $-12.3 \mathrm{~dB},-17.5 \mathrm{~dB}$ and $-22.5 \mathrm{~dB}$ at corresponding frequency. Further this antenna had good gain of $2.09 \mathrm{dBi}, 3.19 \mathrm{dBi}$ and $5.51 \mathrm{dBi}$ at corresponding frequencies. Hence one has to chose that antenna which gives best result. Return loss versus frequency characteristics have been shown in figure 13

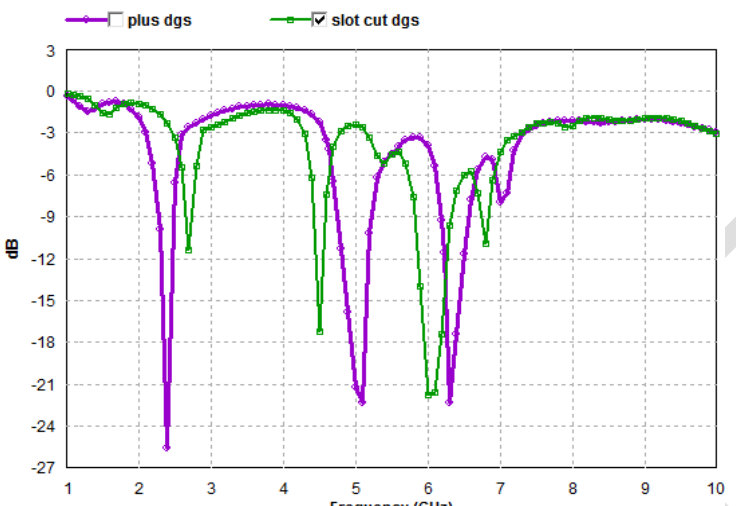

Figure 13: Return Loss Vs Frequency for Proposed Antenna

Results have been compared for plus shaped DGS and slot shaped DGS as mentioned in table 4.

Table 4: Antenna Characteristics by slot and cross DGS

\begin{tabular}{|l|l|l|l|l|l|}
\hline $\begin{array}{l}\text { DGS } \\
\text { Type }\end{array}$ & $\begin{array}{l}\text { Resonance } \\
\text { Frequency } \\
(\mathbf{G H z})\end{array}$ & $\begin{array}{l}\text { Return } \\
\text { Loss } \\
(\mathbf{d B})\end{array}$ & $\begin{array}{l}\text { Gain } \\
(\mathbf{d B i})\end{array}$ & $\begin{array}{l}\text { Directivity } \\
(\mathbf{d B i})\end{array}$ & $\begin{array}{l}\text { Bandwidth } \\
(\mathbf{M H z})\end{array}$ \\
\hline \multirow{5}{*}{ plus } & 2.4 & -24.75 & 2.48 & 5.60 & 100 \\
\cline { 2 - 6 } & 5.1 & -22.5 & 1.95 & 5.34 & 450 \\
\cline { 2 - 6 } & 6.4 & -21.5 & 2.90 & 7.14 & 400 \\
\hline \multirow{4}{*}{ slot } & 2.7 & -12.3 & 2.09 & 6.41 & 100 \\
\cline { 2 - 6 } & 4.5 & -17.5 & 3.19 & 6.51 & 150 \\
\cline { 2 - 6 } & 6 & -22.5 & 5.51 & 9.61 & 400 \\
\hline
\end{tabular}

VII.

CONCLUSION

Multiband $\mathrm{H}$-shaped fractal antenna is obtained by applying fractal geometry .Initially a rectangular patch is taken and fractal geometry is applied. When DGS has been changed in horizontal direction a and Fr-4 has been used as substrate then antenna resonated at $2.7 \mathrm{GHz}, 4.8 \mathrm{GHz}$ and $6.2 \mathrm{GHz}$ with return loss of $-17.66 \mathrm{~dB},-13.6 \mathrm{~dB}$ and $-23.66 \mathrm{~dB}$. This antenna has gain of $6.05 \mathrm{dBi}, 5.6 \mathrm{dBi}$ and $3.66 \mathrm{dBi}$. Results are also obtained for $\mathrm{H}$-shaped fractal patch antenna by applying plus shaped DGS and slot shaped DGS, hence antenna can be used for WLAN applications.

\section{REFERENCES}

1. Varadhan C., Pakkathillam J. Kizhekke, Kanagasabai M., Sivasamy R., Natarajan R. and Palaniswamy S. Kumar, 2013. "Triband Antenna structures for RFID Systems Deploying Fractal Geometry”, IEEE Letters on Antennas and Wireless Propagation, Vol. 12, pp 437-440.

Waladi V., Mohammadi N., Zehforoosh Y., Habashi A. and Nourinia J., 2013. "A Novel Modified Star Triangular Fractal (MSTF) Monopole Antenna for Super Wideband Applications", IEEE Letters on Antennas and Wireless Propagation, Vol. 12, pp 651-654.

3. Kakkar S., Priyadarshini and Rani S., 2013. "New Antenna with Fractal Shaped DGS for Emergency Management Applications", International Journal of Advanced Research in Computer Science and Software Engineering, Vol. 3, Issue 3, pp 721-724.

4. Kumar A., Kaur J. and Singh R., 2013. "Performance Analysis of Different Feeding Techniques", International Journal of Emerging technology and Advanced Engineering", Vol. 3, Issue 3, pp 884-890.

5. Behera S. and Vinoy K. J., 2012. "Multi-Port Network Approach for the Analysis of Dual Band Fractal Microstrip Antennas", IEEE Transactions on Antennas and Propagation, Vol. 60, No. 11, pp 5100-5106. 
ISSN: 2319-8753

\section{International Journal of Innovative Research in Science, Engineering and Technology}

\section{(An ISO 3297: 2007 Certified Organization)}

\section{Vol. 3, Issue 10, October 2014}

Ram V., Anjaria V., Boriya P. and Patel N., 2012. "Design and Development of Switchable Fractal Patch Antenna for GPS Application", International Journal of Engineering and Science, Vol. 1, Issue. 7, pp 46-50.

Moghadasi M. Naser, Sadeghzadeh R. A., Fakheri M., Aribi T., Sedghi T. and Virdee B.S., 2012. "Miniature Hook-Shaped Multiband Antenna for Mobile Applications", IEEE Letters on Antennas and Wireless Propagation, Vol. 11, pp 1096-1099.

8. Oraizi H. and Hedayati S., 2012. "Circular Polarized Multiband Microstrip Antenna Using the Square and Giuseppe Peano Fractals", IEEE Transactions on Antennas and Propagation, Vol. 60, No. 7, pp 3466-3470.

9. Karmakar A., Verma S., Pal M. and Ghatak R., 2012. "An Ultra Wideband Monopole Antenna with Multiple Fractal Slots with Dual Band Rejection Characteristics", Progress in Electromagnetic Research C.”, Vol. 31, pp 185-197.

10. Sun Xu-Bao, Cao Mao-Yong, Hao Jian-Jun and Guo Yin-Jing, 2012. "A rectangular slot antenna with improved bandwidth", International Journal of Electronics and Communications, Elsevier, Vol. 66, pp 465-466

11. Srivatsun G. and Rani S. Subha, 2011. "A Compact Wideband Fractal Cantor Antenna for Wireless Applications", International Journal of Electronics and Communications, Elsevier, Vol. 65, Issue 9, pp 719-723.

12. Liu Wen-Chung, Wu Chao-Ming and Dai Yang, 2011. "Design of Triple Frequency Microstrip Fed Monopole Antenna Using Defected Ground Structure", IEEE Transactions on Antennas and Propagation, Vol. 59, No. 7, pp 2457-2463.

13. Pourahmadazar J., Ghobadi C. and Nourinia J., 2011. "Novel Modified Pythagorean Tree Fractal Monopole Antennas for UWB Applications", IEEE Letters on Antennas and Wireless Propagation, Vol. 10, pp 484-487.

\section{BIOGRAPHY}
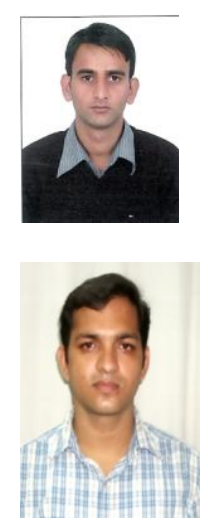

Kapil Thakur: I am pursuing M.Tech from L.R. Institute of Engg. And Technology, Solan, Himachal Pradesh. I have passed B.Tech from Baddi University, Baddi, and Himachal Pradesh in 2007. I have published one research paper in international journal. My fields of interest are Microstrip patch Antenna, fractal geometry, Reconfigurable Antennas.

Sumit Kaushik I am working as Asst. prof. in LRIET Solan Himachal Pradesh from 2013. I have passed my B.Tech and M.Tech from Kurukshetra University, Kurukshetra in 2010 and 2013 respectively. I have published two research papers in international journals and one research paper in IEEE international conference CICN 2013. I have attended several Workshops and lectures organized by IITs. My fields of interest are Microstrip patch Antenna, fractal geometry, Reconfigurable Antennas.

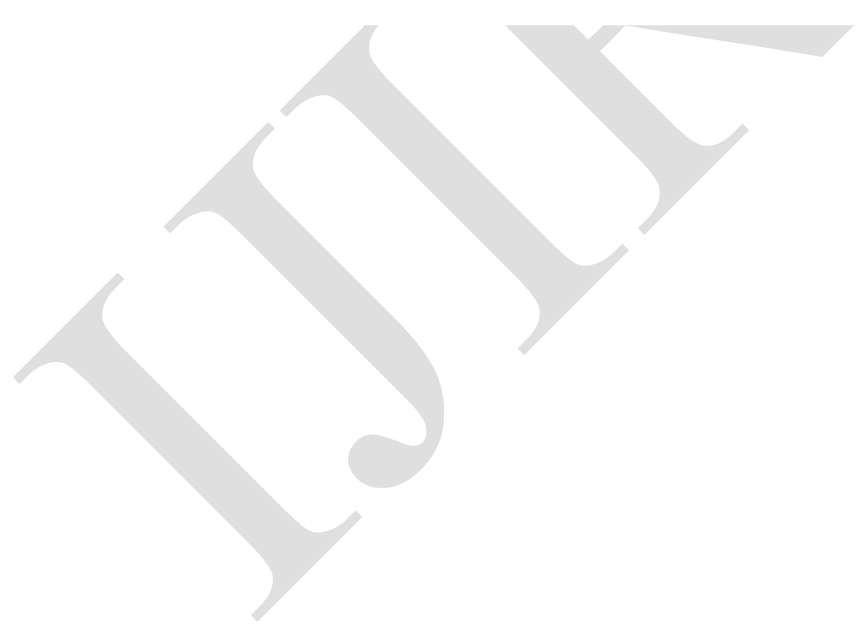

